\title{
Multilevel Determinants of COVID-19 Vaccine Uptake Among South Asian Ethnic Minorities in Hong Kong: Cross-sectional Web-Based Survey
}

Akansha Singh $^{1 *}$, MPH; Angel Hor Yan Lai ${ }^{2,3 *}$, PhD; Jingxuan Wang ${ }^{1}$, MPhil; Saba Asim ${ }^{1}$, MPH; Paul Shing-Fong Chan ${ }^{1}$, MA; Zixin Wang ${ }^{2 *}$, PhD; Eng Kiong Yeoh ${ }^{2 *}$, FRCP

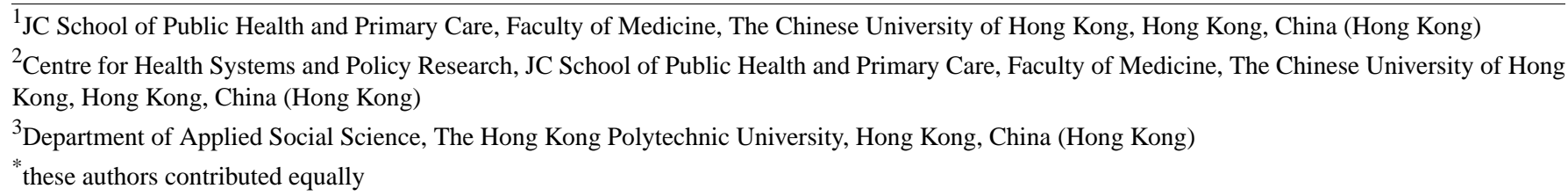

Corresponding Author:

Zixin Wang, PhD

Centre for Health Systems and Policy Research

JC School of Public Health and Primary Care, Faculty of Medicine

The Chinese University of Hong Kong

Room 508, School of Public Health

Prince of Wales Hospital, Shatin, N.T.

Hong Kong, 666888

China (Hong Kong)

Phone: 85222528740

Fax: 85226453098

Email: wangzx@cuhk.edu.hk

\section{Abstract}

Background: The COVID-19 pandemic continues to have a disproportionate effect on ethnic minorities. Across countries, greater vaccine hesitancy has been observed among ethnic minorities. After excluding foreign domestic helpers, South Asians make up the largest proportion of ethnic minorities in Hong Kong. It is necessary to plan for COVID-19 vaccination promotional strategies that cater to the unique needs of South Asians in Hong Kong.

Objective: This study investigated the prevalence of COVID-19 vaccine uptake among a sample of South Asians in Hong Kong. We examined the effects of sociodemographic data and factors at individual level (perceptions), interpersonal level (information exposure on social media), and sociostructural level (cultural) based on the socioecological model.

Methods: A cross-sectional web-based survey was conducted on May 1-31, 2021. Participants were South Asian people aged 18 years or older living in Hong Kong; able to comprehend English, Hindi, Nepali, or Urdu; and having access to a smartphone. Three community-based organizations providing services to South Asians in Hong Kong facilitated the data collection. The staff of the community-based organizations posted the study information in WhatsApp groups involving South Asian clients and invited them to participate in a web-based survey. Logistic regression models were fit for data analysis.

Results: Among 245 participants, 81 (33.1\%) had taken at least one dose of the COVID-19 vaccine (one dose, 62/245, 25.2\%; and both doses, 19/245, 7.9\%). After adjusting for significant background characteristics, cultural and religious reasons for COVID-19 vaccine hesitancy were associated with lower COVID-19 vaccine uptake (adjusted odds ratio [AOR] 0.83, 95\% CI 0.71-0.97; $P=.02$ ). At the individual level, having more positive attitudes toward COVID-19 vaccination (AOR 1.31, 95\% CI $1.10-1.55 ; P=.002$ ), perceived support from significant others (AOR 1.29, 95\% CI 1.03-1.60; $P=.03$ ), and perceived higher behavioral control to receive COVID-19 vaccination (AOR 2.63, 95\% CI 1.65-4.19; $P<.001$ ) were associated with higher COVID-19 vaccine uptake, while a negative association was found between negative attitudes and the dependent variable (AOR 0.73, 95\% CI 0.62-0.85; $P<.001)$. Knowing more peers who had taken the COVID-19 vaccine was also associated with higher uptake (AOR 1.39, 95\% CI 1.11-1.74; $P=.01$ ). At the interpersonal level, higher exposure to information about deaths and other serious conditions caused by COVID-19 vaccination was associated with lower uptake (AOR 0.54, 95\% CI 0.33-0.86; $P=.01$ ). 
Conclusions: In this study, one-third (81/245) of our participants received at least one dose of the COVID-19 vaccine. Cultural or religious reasons, perceptions, information exposure on social media, and influence of peers were found to be the determinants of COVID-19 vaccine uptake among South Asians. Future programs should engage community groups, champions, and faith leaders, and develop culturally competent interventions.

(JMIR Public Health Surveill 2021;7(11):e31707) doi: 10.2196/31707

\section{KEYWORDS}

COVID-19; South Asian ethnic minorities; COVID-19 vaccination; uptake; cultural and religious reasons for vaccine hesitancy; perceptions; information exposure on social media; influence of peers; socioecological model; Hong Kong

\section{Introduction}

The COVID-19 pandemic is an ongoing threat [1]. COVID-19 vaccination and other behavioral preventive measures can help to eradicate this pandemic. The Hong Kong government procured 2 types of COVID-19 vaccines (Sinovac-Biotech and BioNTech-Fosun Pharma) and implemented a free-of-charge territory-wide vaccination program to all Hong Kong residents aged 16 years or older. The vaccination services were provided through community vaccination centers, designated public and private clinics, and outreach vaccination services at residential care homes or nursing homes [2]. The program aimed to cover the entire Hong Kong population. During the study period (May 1-31, 2021), priorities to receive COVID-19 vaccination were given to the following groups of Hong Kong residents: (1) individuals aged 30 years or older and caregivers of older adults aged more than 70 years; (2) personnel in health care settings and those participating in antiepidemic-related work; (3) residents and staff of residential care homes for the older adults/persons with disabilities; (4) personnel maintaining critical public services; (5) those providing cross-boundary transportation or working at control points/ports; (6) staff of food and beverage premises; (7) staff of local public transportation operators; (8) registered construction workers; (9) staff of property management; (10) teachers and school staff; (11) staff of tourism industry; (12) staff of scheduled premises under the Prevention and Control of Disease Regulation (eg, staff of fitness centers, beauty parlors); (13) students studying outside Hong Kong (aged 16 years or older); and (14) domestic helpers [2]. The latest estimate shows that at least $70 \%$ immune individuals would be necessary to achieve herd immunity for COVID-19 [3]. The number of people who received at least one dose of COVID-19 vaccine increased from 936,400 on May 1, 2021 to $1,379,400$ on May 31, 2021, accounting for $12.3 \%$ and $18.2 \%$ of the entire population in Hong Kong, respectively [4]. However, it will take about 1 year for Hong Kong to achieve herd immunity based on the current progress.

Across countries, COVID-19 pandemic continues to have a disproportionate effect on ethnic minorities, with higher COVID-19 morbidity and mortality and greater adverse socioeconomic consequences [5]. With mass COVID-19 vaccination programs in progress, disparities in its uptake may aggravate the vulnerability of ethnic minorities. Across countries, greater vaccine hesitancy has been observed among people from some ethnic minorities [5-7]. In the United Kingdom, vaccine hesitancy was higher among Black, Bangladeshi, and Pakistani people compared with people from a White ethnic background [8]. Two other studies reported lower COVID-19 vaccine uptake rates among ethnic minorities who were older than 80 years (20.5\% among Black people vs $42.5 \%$ among White people) and those who were health care workers (70.9\% White people, 58.5\% South Asians, and 36.8\% Black people) $[9,10]$. It is hence important to understand and address the disparities in COVID-19 vaccination among ethnic minorities.

In Hong Kong, the ethnic minority population increased significantly by $70.8 \%$ from 2006 to 2016 and accounted for $8.0 \%(n=584,383)$ of the entire population (Census, 2016) [11]. After excluding foreign domestic helpers (most of them are Filipinos and Indonesians), South Asians, including Indians, Pakistanis, Nepalis, Bangladeshis, and Sri Lankans make up the largest proportion of the ethnic minorities in Hong Kong $(n=85,875$, accounting for $1.2 \%$ of the entire Hong Kong population) [11]. A recent study found that health system responsiveness reported by South Asians was lower than that reported by Chinese patients for both outpatient and inpatient services in Hong Kong [12]. The largest disparity in the responsiveness was shown in the communication barriers experienced by South Asians owing to cultural and language differences between South Asian patients and local health care service providers [12]. During hospitalization, South Asian inpatients perceived limited access to community support in comparison with the Chinese inpatients [12]. There is also a lack of autonomy in decision-making and choice of health care providers experienced by South Asians [12]. Health professionals in Hong Kong also indicated barriers in their delivery of services to the ethnic minorities, including inadequate dissemination of appropriate information, insufficient provision of cross-cultural care education and training, inadequate availability of public primary care services, and presence of bias and discrimination among hospital staff [12]. Cultural differences between ethnic minorities and health service providers affect patient-provider interactions and health care quality, resulting in mistrust of government and health authorities, which in turn becomes an obstacle for the COVID-19 vaccination program [5]. With an increasing population of South Asians in Hong Kong, it is necessary to plan for COVID-19 vaccination promotional strategies that cater to their unique needs.

This study applied the socioecological model as the conceptual framework, which considered determinants of a health behavior at the individual, interpersonal, and sociostructural levels [13]. An intervention addressing factors at multiple levels is more likely to be successful in changing behavior [13]. At the 
sociostructural level, previous studies have pointed out the association between cultural/religious belief and COVID-19 vaccine hesitancy. A Malaysian study showed that $20.8 \%$ and $6.8 \%$ of the ethnic minorities believed that their COVID-19 vaccine hesitancy was caused by concerns regarding religious and cultural factors, respectively [14]. News reports also suggested that there were concerns among Muslims over the halal status of the COVID-19 vaccine [15], and the beliefs that COVID-19 should be healed by God and the body is sacred were cited as reasons to refuse the COVID-19 vaccine [16]. Because a large percentage of the South Asians in Hong Kong are Muslims, there is a need to understand the effects of religious beliefs on COVID-19 vaccine uptake, so that policymakers can target this specific population for the relevant COVID-19 vaccine promotional strategy. Limited evidence is available to date to inform us on the cultural effect of COVID-19 vaccine uptake in Hong Kong.

At the interpersonal level, misinformation related to COVID-19 vaccination threatened vaccine uptake [17]. The government used to report deaths after COVID-19 vaccination, regardless of the existence of the direct causality evidence. Such information exposure might inhibit the motivation to receive COVID-19 vaccination among South Asians as they will associate COVID-19 vaccination directly with deaths. For example, public's concerns about vaccine safety increased substantially after media reported deaths after COVID-19 vaccination, which resulted in a drop in the proportion of people turning up for their vaccination appointment in Hong Kong (from $>90 \%$ to $72 \%$ ) [2]. However, communication with peers may be effective among South Asians owing to higher level of rapport between people of the same ethnicity [18]. The Social Learning Theory posits that observation of peers has a major influence on people's health behaviors. Therefore, vaccinated peers may play important roles as volunteers in future programs promoting COVID-19 vaccination among South Asians by sharing their positive experience. Peers' experiences related to COVID-19 vaccination might have a strong influence on South Asians' decision to receive such vaccinations. Based on these observations, socialization, in terms of receiving vaccine-related information or interpersonal interaction, is assumed to affect vaccine uptake.

At the individual level, the Theory of Planned Behavior (TPB) postulates that in order to perform a behavior, one would evaluate the pros and cons of the behavior (positive and negative attitudes), consider whether their significant others would support such behavior (perceived subjective norm), and appraise how much control one has over the behavior (perceived behavioral control) [19]. The TPB was commonly used to explain a health behavior and guide the behavioral intervention [20,21]; it has been used to explain willingness to receive COVID-19 vaccination among Chinese people [22]. Studies conducted among the Hong Kong general population identified the perceived pros and cons that were associated with the willingness to receive COVID-19 vaccination. Pros included perceived greater risk and severe consequences of infection, perceived higher effectiveness of COVID-19 vaccines, perceived greater impact of COVID-19 vaccination in pandemic control, perceived larger proportion of general public and acquaintance would take up such vaccination, being recommended by physicians and family members, and perceived higher behavioral control to take up the vaccination [23-26]. Concerns related to side effects and access issues as well as difficulties in choosing one out of the available COVID-19 vaccines were commonly mentioned as cons against vaccination [23-26]. These perceptions were considered by this study. To our knowledge, there is a dearth of studies investigating the determinants of COVID-19 vaccine uptake among ethnic minorities in the Asian region. To address the knowledge gaps, this study investigated the prevalence of COVID-19 vaccine uptake among a sample of South Asians in Hong Kong. We examined the effects of factors, including sociodemographic data, and all 3 levels of factors based on the socioecological model.

\section{Methods}

\section{Study Design}

We conducted a cross-sectional web-based survey of 245 South Asian adults in Hong Kong, China on May 1-31, 2021.

\section{Participants and Data Collection}

Participants were South Asian people aged 18 years or older living in Hong Kong; able to comprehend English, Hindi, Nepali, or Urdu; and having access to a smartphone. Three community-based organizations (CBOs) in Hong Kong facilitated the data collection. These $\mathrm{CBO}$ s provide a wide range of services to ethnic minorities, including early childhood education, child rehabilitation, school social work, treatment and social rehabilitation for drug abusers, home care for older adults, employee assistance and development, health check-up, and health education. However, their services do not include provision of COVID-19 vaccination. The CBOs keep a list of South Asian people using their services and WhatsApp groups involving CBO staff, and these service users are established. There are around 1050 active South Asian people in the WhatsApp groups held by the CBOs. CBO staff posted the study information in the WhatsApp groups and invited South Asian people in these groups to participate in the web-based survey. A link to access a web-based self-administered survey was also posted in the WhatsApp groups. Through the link, participants first selected the language of the survey (English, Hindi, Nepali, or Urdu) and then accessed an electronic consent form. On the form, they read the study information and a statement indicating that the information collected by the survey was only used for scientific research purposes and would be kept strictly confidential. Participation was completely voluntary, and refusal would have no consequences. After clicking "I agree" on the electronic consent form, they could start the web-based survey. We developed the questionnaire by using Google forms, a commonly used web-based survey platform. Each WhatsApp account was only allowed to access the web-based questionnaire once to avoid duplicate responses. The survey had about 100 items, which took about 20 minutes to complete. The Google form performed a completeness check before each questionnaire was submitted. Participants were able to review and change their responses before submission. Participants were asked to leave an address at the end of the survey. The procedure of data collection is shown in Figure 1. A supermarket coupon of HK 
\$50 (US \$6.5) was sent to the participants by mail upon completion. All data were stored in the web-based server of the
Google form and protected by a password. Only the corresponding author had access to the database.

Figure 1. Flowchart of data collection.

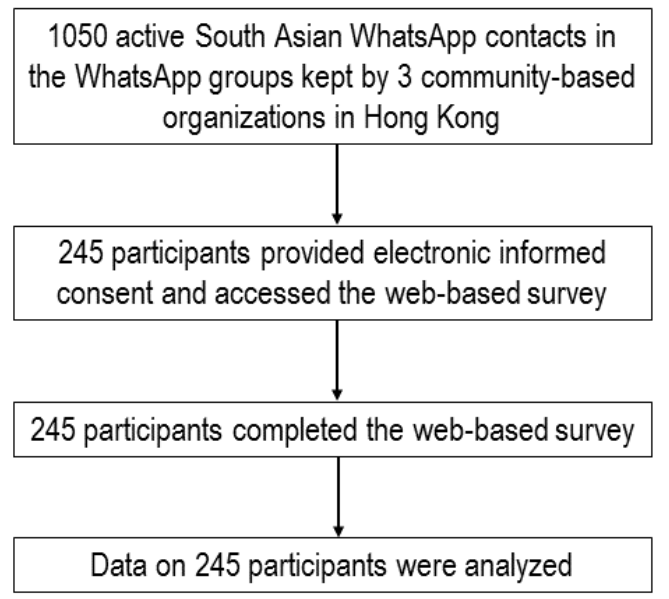

\section{Ethics Approval and Consent to Participate}

Informed consent was obtained from all the participants involved in this study. Ethical approval was obtained from the Survey and Behavioral Research Committee of the Chinese University of Hong Kong (Reference SBRE-20-534).

\section{Sample Size Planning}

Our target sample size was 250. Given a statistical power of .80 and an $\alpha$ value of .05 and assuming the COVID-19 vaccine uptake in the reference group (without a facilitating condition) to be $10 \%-20 \%$, the sample size could detect the smallest odds ratio of 2.23 between people with and without the facilitating conditions (PASS 11.0, NCSS LLC).

\section{Measurements}

\section{Development of the Questionnaire}

A panel consisting of public health researchers, social workers, health psychologists, representatives from South Asian communities, and CBO workers was formed to develop the questionnaire. Bilingual researchers with master's degrees translated the English version of the questionnaire into Hindi, Nepali, or Urdu. The agreed versions were back translated into English by independent bilingual researchers to ensure linguistic equivalence. The questionnaire was tested on the readability and length among 20 South Asians speaking English, Hindi, Nepali, or Urdu. All participants in the pilot testing agreed that the wordings of the questions were appropriate and easy to understand. However, 15 of them commented that the questionnaire was too long. The panel trimmed down the questionnaire from 130 items to 100 items. Thereafter, the participants were invited to comment on the length of the revised questionnaire, and they all agreed that the length was acceptable. The panel then finalized the questionnaire for the actual survey. The English version of the questionnaire is in Multimedia Appendix 1.

\section{Background Characteristics}

Participants were asked to report on sociodemographic data and living arrangements (eg, number of family members living with them, whether they were living with children younger than 18 years or older adults aged $\geq 60$ years). Participants also reported compliance to personal preventive behaviors in the past month, including frequency of wearing facemasks when having close contact with others in workplaces and other public spaces and sanitizing hands after returning from public spaces or touching public installation (response categories: every time, often, sometimes, and never). Two physical distancing behaviors were also measured (whether they avoided social or meal gatherings with people who they do not live with and crowded places in the past month). Same measurements of personal preventive behaviors and physical distancing were used in published studies $[19,22,27,28]$.

\section{COVID-19 Vaccine Uptake}

Participants reported whether they had taken any COVID-19 vaccine. Some supplementary information was collected from the vaccinated participants, including number of doses and types of COVID-19 vaccines received, presence of side effects, and severity of such side effects.

\section{Individual-, Interpersonal-, and Sociostructural-Level Variables Related to COVID-19 Vaccination}

At the individual level, positive attitudes toward COVID-19 vaccination were measured by the validated Chinese version of the Positive Attitude Scale [19]. The original scale has 5 items, and the Cronbach $\alpha$ was .84 [19]. The scale was adapted by replacing "China" in the original scale with "Hong Kong." Perceived subjective norm related to COVID-19 vaccination was measured by the validated Chinese version of the Subjective Norm Scale [19]. The Cronbach $\alpha$ of the original 2-item scale was .85. We added 1 more item "your friends from South Asia would support you to receive COVID-19 vaccination" to the original scale. Regarding perceived behavioral control related to COVID-19 vaccination, we added 1 more item "you are confident to receive COVID-19 vaccination in the next six 
months if you want to" to the validated single-item measurement [19]. One scale (6 items) was constructed for this study to measure negative attitudes toward COVID-19 vaccination (eg, the side effects of COVID-19 vaccines in the long run is unclear). The response categories to the aforementioned scale items were 1 (disagree), 2 (neutral), and 3 (agree). In addition, one single item was constructed to measure the descriptive norm related to COVID-19 vaccination "Among South Asians you know who are living in Hong Kong, how many of them have already taken up COVID-19 vaccines?" (response categories: $1=$ none/not sure, $2=1-2,3=3-5,4=6-10$, and $5=$ more than 10 ). At the interpersonal level, the frequency of exposing to negative information related to COVID-19 vaccination on social media (eg, Facebook, Twitter, Flicker, TikTok) in the past were measured (response categories: $0=$ almost never, $1=$ seldom, $2=$ sometimes, and 3=always). Participants were also asked about whether they heard about any South Asians who experienced serious side effects after taking up COVID-19 vaccines. At the sociostructural level, 5 items measured cultural and religious reasons for COVID-19 vaccine hesitancy (eg, you are concerned about the halal status of the COVID-19 vaccines and the body is sacred; it should not receive certain chemicals or blood or tissues from animals). The Cultural and Religious Barrier Scale was constructed by summing up individual item scores. In addition, 2 items measured how much confidence they had in Hong Kong's health care system and how much they trusted the Hong Kong government regarding COVID-19 control (response categories: from $1=$ not at all to $10=$ extremely).

\section{Statistical Analysis}

Self-reported uptake of any COVID-19 vaccine was the dependent variable. Univariate logistic regression models first assessed the significance of the association between background characteristics and the dependent variable. We fitted a single logistic regression model to obtain adjusted odds ratios (AOR), which involved one of the independent variable of interest and all background characteristics with $P$ values less than .05 in univariate analysis. The same approach to obtain AOR was commonly used in published studies [19,20,22,27,28]. There was no missing value for the participants who completed the survey. Therefore, missing value analysis was not performed. SPSS version 26.0 (IBM Corp) was used for data analysis, with $P<.05$ considered statistically significant.

\section{Results}

\section{Background Characteristics}

Among the 245 participants who completed the web-based survey, 83 (33.9\%) were Indians, $89(36.3 \%)$ were Pakistanis, $52(21.2 \%)$ were Nepalis, and $21(8.6 \%)$ were from other ethnicity groups. The majority of the participants were younger than 40 years, females, married or cohabited with a partner, and with tertiary education. About 29.4\% (72/245) of the participants were Hong Kong permanent residents and had a full-time job. Participants reported good compliance with personal preventive behaviors and physical distancing behaviors in the past month (Table 1). 
Table 1. Background characteristics of the South Asians who completed the web-based survey in Hong Kong on May 1-31, 2021 (N=245).

\begin{tabular}{|c|c|}
\hline Characteristics & Values, n (\%) \\
\hline \multicolumn{2}{|l|}{ Sociodemographic characteristics } \\
\hline \multicolumn{2}{|l|}{ Age group (years) } \\
\hline $18-29$ & $83(33.9)$ \\
\hline $30-39$ & $100(40.8)$ \\
\hline $40-49$ & $55(22.4)$ \\
\hline$\geq 50$ & $7(2.9)$ \\
\hline \multicolumn{2}{|l|}{ Gender } \\
\hline Male & $83(33.9)$ \\
\hline Female & $162(66.1)$ \\
\hline \multicolumn{2}{|l|}{ Relationship status } \\
\hline Currently single & $90(36.7)$ \\
\hline Married or cohabiting with a partner & $155(63.3)$ \\
\hline \multicolumn{2}{|l|}{ Ethnicity } \\
\hline Indian & $83(33.9)$ \\
\hline Pakistani & $89(36.3)$ \\
\hline Nepali & $52(21.2)$ \\
\hline Other ethnicity groups & $21(8.6)$ \\
\hline \multicolumn{2}{|l|}{ Permanent residents of Hong Kong } \\
\hline Yes & $72(29.4)$ \\
\hline No & $173(70.6)$ \\
\hline \multicolumn{2}{|l|}{ Highest education level attained } \\
\hline Junior high or below & $35(14.3)$ \\
\hline Senior high or equivalent & $64(26.1)$ \\
\hline College or university & $103(42.0)$ \\
\hline Postgraduate & $43(17.6)$ \\
\hline \multicolumn{2}{|l|}{ Employment status } \\
\hline Full-time & $85(34.7)$ \\
\hline Part-time/self-employed/housewife/unemployed/retired/students & $160(65.3)$ \\
\hline \multicolumn{2}{|l|}{ Family members living with the participant } \\
\hline 0 & $15(6.1)$ \\
\hline $1-2$ & $44(18.0)$ \\
\hline $3-4$ & $124(50.6)$ \\
\hline$\geq 5$ & $62(25.3)$ \\
\hline \multicolumn{2}{|l|}{ Living with an older adult aged $\geq 60$ years } \\
\hline No & $69(28.2)$ \\
\hline Yes & $176(71.8)$ \\
\hline \multicolumn{2}{|l|}{ Living with a child aged $<18$ years } \\
\hline No & $181(73.9)$ \\
\hline Yes & $64(26.1)$ \\
\hline \multicolumn{2}{|l|}{ Having at least one chronic condition } \\
\hline No & $221(90.2)$ \\
\hline Yes & $24(9.8)$ \\
\hline
\end{tabular}




\begin{tabular}{ll}
\hline Characteristics & Values, $\mathrm{n}(\%)$ \\
\hline Compliance to personal preventive behaviors and physical distancing & \\
Frequency of facemask wearing when in proximity with other people in workplace & $20(8.2)$ \\
Never/sometimes/often & $225(91.8)$ \\
Every time & \\
Frequency of facemask wearing in public spaces/transportations other than workplaces & $46(18.8)$ \\
Never/sometimes/often & $199(81.2)$ \\
Every time & $60(24.5)$ \\
Sanitizing hands after returning from public spaces or touching public installation & $185(75.5)$ \\
Never/sometimes/often & \\
Every time & $65(26.5)$ \\
Avoiding social/meal gathering with other people who do not live together & $180(73.5)$ \\
No & \\
Yes & \\
Avoiding crowded places & $59(24.1)$ \\
No & $186(75.9)$ \\
Yes &
\end{tabular}

\section{COVID-19 Vaccine Uptake}

Among the participants, $33.1 \%$ (81/245) had received at least one dose of COVID-19 vaccine (one dose, 62/245, 25.2\%; both doses, 19/245, 7.9\%). Among the vaccinated participants
(81/245), most of them chose mRNA vaccines manufactured by the BioNTech-Fosun Pharma and received vaccination at community vaccination centers. The side effects of the COVID-19 vaccination were reported by 64 participants (79\%), and most of the side effects were very mild/mild (Table 2). 
Table 2. Perceptions and influences of social media and peers related to COVID-19 vaccination among South Asians who completed the web-based survey in Hong Kong on May 1-31, $2021(\mathrm{~N}=245)$.

\begin{tabular}{lr}
\hline Characteristics & Values \\
\hline Uptake of at least one dose of COVID-19 vaccine, $\mathbf{n}(\%)$ & $164(66.9)$ \\
No & $81(33.1)$ \\
Yes & 8
\end{tabular}

Individual-level factors, $\mathrm{n}(\%)$

Perceptions related to COVID-19 vaccination based on the Theory of Planned Behavior

Positive attitudes toward COVID-19 vaccination (agree)

COVID-19 vaccination is highly effective in protecting you from COVID-19

Taking up COVID-19 vaccination is highly effective in protecting your family members against COVID- 136 (55.5) 19

Taking up COVID-19 vaccination can facilitate resumption of cross-boundary travelling

Taking up COVID-19 vaccination can contribute to the control of COVID-19 in Hong Kong

Hong Kong will have adequate supply of COVID-19 vaccination

Positive Attitude Scale ${ }^{\mathrm{a}}$, mean (SD)

\section{Negative attitudes toward COVID-19 vaccination (agree)}

COVID-19 vaccines will have severe side effects

The side effects of COVID-19 vaccines in the long run is unclear

The protection of COVID-19 vaccines will only last for a short time

It is difficult for you to register for COVID-19 vaccination

$21(8.6)$

There is a lack of information related to the COVID-19 vaccination program in my mother tongue

You do not know which type of COVID-19 vaccine is the most suitable for you

Negative Attitude Scale ${ }^{\mathrm{b}}$, mean (SD)

\section{Perceived subjective norm related to COVID-19 vaccination (agree)}

Doctors and nurses would support you to receive COVID-19 vaccination

Your family members will support you to receive COVID-19 vaccination

Your friends from South Asia would support you to receive COVID-19 vaccination

Subjective Norm Scale ${ }^{\mathrm{c}}$, mean (SD)

Perceived behavioral control related to COVID-19 vaccination (agree)

Receiving COVID-19 vaccination is easy for you if you want to

You are confident to receive COVID-19 vaccination in the next 6 months if you want to

Perceived Behavioral Control Scale ${ }^{\mathrm{d}}$, mean (SD)

Among South Asians you know who are living in Hong Kong, how many of them have already taken up COVID-19 vaccines?

$\begin{array}{lc}0 / \text { not sure } & 54(22.0) \\ 1-2 & 34(13.9) \\ 3-5 & 51(20.8) \\ 6-10 & 29(11.8) \\ >10 & 77(31.4)\end{array}$

Interpersonal-level factors, $\mathbf{n}(\%)$

Frequency of exposure to the following information related to COVID-19 vaccination on social media (sometimes/always)

Positive information related to COVID-19 vaccination (eg, promising efficacy of the vaccines, new vaccines 151 (61.6) will enter the market soon)

COVID-19 vaccination will cause deaths and other serious conditions 


\begin{tabular}{|c|c|}
\hline Characteristics & Values \\
\hline Many people in Hong Kong did not turn up for their appointment to receive COVID-19 vaccination & $109(44.5)$ \\
\hline \multicolumn{2}{|l|}{ Influence of peers } \\
\hline \multicolumn{2}{|l|}{ Did you hear about any South Asians who experienced serious side effects after taking up COVID-19 vaccines? } \\
\hline No & $188(76.7)$ \\
\hline Yes & $57(23.3)$ \\
\hline \multicolumn{2}{|l|}{ Sociostructural-level factors , $\mathrm{n}(\%)$} \\
\hline \multicolumn{2}{|l|}{ Cultural and religious reasons for COVID-19 vaccination hesitancy (agree) } \\
\hline You are concerned about the halal status of the COVID-19 vaccines & $66(26.9)$ \\
\hline $\begin{array}{l}\text { You are concerned that COVID-19 vaccines may not work well among South Asians, as they are developed } \\
\text { by China and western countries }\end{array}$ & $54(22.0)$ \\
\hline The body is sacred; it should not receive certain chemicals or blood or tissues from animals & $61(24.9)$ \\
\hline COVID-19 should be healed by God or natural means & $54(22.0)$ \\
\hline Taking up vaccination is violating God's will & $12(4.9)$ \\
\hline Cultural and Religious Barrier Scale ${ }^{\mathrm{e}}$, mean (SD) & $8.3(2.5)$ \\
\hline Level of confidence in Hong Kong's health system, mean (SD) & $7.2(2.1)$ \\
\hline Level of trust of the Hong Kong government regarding COVID-19 control, mean (SD) & $7.7(2.1)$ \\
\hline
\end{tabular}

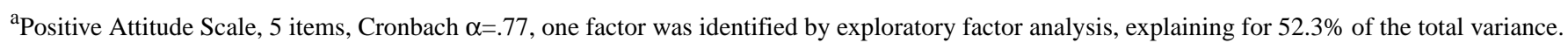
${ }^{\mathrm{b}}$ Negative Attitude Scale, 6 items, Cronbach $\alpha=.61$, one factor was identified by exploratory factor analysis, explaining for $47.8 \%$ of the total variance. ${ }^{\mathrm{c}}$ Subjective Norm Scale, 3 items, Cronbach $\alpha=.60$, one factor was identified by exploratory factor analysis, explaining for $56.9 \%$ of the total variance. ${ }^{\mathrm{d}}$ Perceived Behavioral Control Scale, 2 items, Cronbach $\alpha=.63$, one factor was identified by exploratory factor analysis, explaining for $73.0 \%$ of the total variance.

${ }^{\mathrm{e}} \mathrm{Cultural}$ and Religious Barrier Scale, 5 items, Cronbach $\alpha=.65$, one factor was identified by exploratory factor analysis, explaining for $42.2 \%$ of the total variance.

\section{Individual-, Interpersonal-, and Sociostructural-Level Variables Related to COVID-19 Vaccination}

The Cronbach $\alpha$ of the scales based on the TPB ranged from .60 to .77 ; single factors were identified by exploratory factor analysis, explaining for $47.8 \%-73 \%$ of the total variance. Among the participants, $31.4 \%$ (77/245) had at least 10 peers who had received COVID-19 vaccination. About half of the participants were sometimes/always exposed to the following COVID-19 vaccination-related information on social media such as positive information (eg, promising efficacy of the vaccines, and new vaccines will enter the market soon) (151/245, 61.6\%), COVID-19 vaccination will cause deaths and other serious conditions (120/245, 49.0\%), and many people in Hong Kong did not turn up for their appointment to receive COVID-19 vaccination (109/245, 44.5\%). Regarding the sociostructural-level variables, the Cronbach $\alpha$ of the Cultural and Religious Barrier Scale was .65; one factor was identified by exploratory factor analysis, explaining for $42.2 \%$ of the total variance (Table 2).

\section{Factors Associated With COVID-19 Vaccine Uptake}

In univariate analysis, age group, ethnicity, relationship status, status as Hong Kong permanent residents, facemask wearing in public spaces/transportations other than workplaces, sanitizing hands after returning from public spaces or touching public installation, and avoiding social/meal gatherings with other people who do not live together were associated with COVID-19 vaccine uptake (Table 3 ). 
Table 3. Associations between background characteristics and COVID-19 vaccine uptake among the South Asians who completed the web-based survey in Hong Kong on May 1-31, 2021 ( $\mathrm{N}=245)$.

\begin{tabular}{|c|c|c|}
\hline $\begin{array}{l}\text { Participants who had taken the } \\
\text { COVID-19 vaccine }(\mathrm{n}=81), \mathrm{n} \\
(\%)\end{array}$ & $\begin{array}{l}\text { Participants who had not taken } \\
\text { the COVID-19 vaccine }(\mathrm{n}=164) \text {, } \\
\mathrm{n}(\%)\end{array}$ & $\begin{array}{l}\text { Crude odds ratio } \\
(95 \% \mathrm{CI})\end{array}$ \\
\hline
\end{tabular}

\section{Sociodemographic data}

Age group (years)

$\begin{array}{ll}18-29 & 10(12.3) \\ 30-39 & 42(51.9) \\ 40-49 & 27(33.3) \\ \geq 50 & 2(2.5)\end{array}$

Gender

$\begin{array}{ll}\text { Male } & 24(29.6) \\ \text { Female } & 57(70.4)\end{array}$

Relationship status

Currently single

$20(24.7)$

Married or cohabited with a partner

$61(75.3)$

\section{Ethnicity}

Indian $33(40.7)$

Pakistani $16(19.8)$

Nepali

$25(30.9)$

Other ethnicity groups

7 (8.6)

Permanent residents of Hong Kong

$\begin{array}{ll}\text { Yes } & 36(44.4) \\ \text { No } & 45(55.6)\end{array}$

Highest education level attained

Junior high or below
Senior high or equivalent
College or university
Postgraduate

$11(13.6)$

$15(18.5)$

38 (46.9)

17 (21.0)

\section{Employment status}

$\begin{array}{ll}\text { Full-time } & 32(39.5) \\ \text { Others } & 49(60.5)\end{array}$

Family members living with the participant

$\begin{array}{ll}0 & 7(8.6) \\ 1-2 & 19(23.5) \\ 3-4 & 39(48.1) \\ \geq 5 & 16(19.8)\end{array}$

Living with an older adult aged $\geq 60$ years
No
$61(75.3)$
Yes
$20(24.7)$

Living with a child younger than 18 years
No
17 (21.0)
Yes
$64(79.0)$

$73(44.5)$

$58(35.4)$

28 (17.1)

$5(3.0)$

1.0

$\mathrm{N} / \mathrm{A}^{\mathrm{a}}$

$5.29(2.45-11.43) \quad<.001$

$7.04(3.02-16.41) \quad<.001$

$2.92(0.50-17.11) \quad .24$

59 (36.0)

1.0

N/A

$105(64.0)$

$1.34(0.75-2.37) \quad .32$

70 (42.7)

1.0

N/A

$94(57.3)$

$2.27(1.26-4.11)$

.007

$50(30.5)$

1.0

N/A

73 (44.5)

$0.33(0.17-0.67) \quad .002$

27 (16.5)

$1.40(0.70-2.82) \quad .34$

$14(8.5)$

$0.76(0.28-2.08) \quad .59$

$36(22.0)$

1.0

N/A

$128(78.0)$

$0.35(0.20-0.62) \quad<.001$

24 (16.4)

1.0

N/A

49 (29.9)

$0.67(0.27-1.67) \quad .39$

65 (39.6)

$1.28(0.56-2.89) \quad .56$

$26(15.9)$

$1.43(0.56-3.65) \quad .46$

$53(32.3)$

1.0

N/A

$111(67.7)$

$0.73(0.42-1.27)$

.27

8 (4.9)

1.0

N/A

25 (15.2)

$0.87(0.27-2.82) \quad .81$

85 (51.8)

$0.52(0.18-1.55) \quad .24$

$46(28.0)$

$0.40(0.12-1.27) \quad .12$

$120(73.2)$

1.0

N/A

44 (26.8)

$0.89(0.49-1.65) \quad .72$

52 (31.7)

1.0

N/A

$112(68.3)$

$1.75(0.93-3.28)$

Having at least one chronic condition 


\begin{tabular}{|c|c|c|c|c|}
\hline & $\begin{array}{l}\text { Participants who had taken the } \\
\text { COVID-19 vaccine }(\mathrm{n}=81), \mathrm{n} \\
(\%)\end{array}$ & $\begin{array}{l}\text { Participants who had not taken } \\
\text { the COVID-19 vaccine }(n=164) \text {, } \\
n(\%)\end{array}$ & $\begin{array}{l}\text { Crude odds ratio } \\
(95 \% \mathrm{CI})\end{array}$ & $P$ value \\
\hline No & 74 (91.4) & 147 (89.6) & 1.0 & N/A \\
\hline Yes & $7(8.6)$ & $17(10.4)$ & $0.82(0.33-2.06)$ & .62 \\
\hline
\end{tabular}

Compliance to personal preventive behaviors and physical distancing

Frequency of facemask wearing when in proximity with other people in workplace

N/A

$\begin{array}{lllll}\text { Never/sometimes/often } & 10(12.3) & 36(22.0) & 1.0 \\ \text { Every time } & 71(87.7) & 128(78.0) & 2.00(0.94-4.26) & .07\end{array}$

Frequency of facemask wearing in public spaces/transportations other than workplaces

$\begin{array}{lllll}\text { Never/sometimes/often } & 1(1.2) & 19(11.6) & 1.0 & \text { N/A } \\ \text { Every time } & 80(98.8) & 145(88.4) & 10.48(1.38-79.76) & .02\end{array}$

Sanitizing hands after returning from public spaces or touching public installation

\begin{tabular}{|c|c|c|c|c|}
\hline Never/sometimes/often & $13(16.0)$ & $47(28.7)$ & 1.0 & N/A \\
\hline Every time & $68(84.0)$ & 117 (71.3) & $2.10(1.06-4.16)$ & .03 \\
\hline
\end{tabular}

Avoiding social/meal gathering with other people who do not live together

$\begin{array}{lllll}\text { No } & 15(18.5) & 50(30.5) & 1.0 & \text { N/A } \\ \text { Yes } & 66(81.5) & 114(69.5) & 1.93(1.01-3.70) & .048\end{array}$

Avoiding crowded places

$\begin{array}{lllll}\text { No } & 14(17.3) & 45(27.4) & 1.0 & \text { N/A } \\ \text { Yes } & 67(82.7) & 119(72.6) & 1.81(0.93-3.54) & .08\end{array}$

${ }^{\mathrm{a}} \mathrm{N} / \mathrm{A}$ : not applicable.

After adjusting for significant background characteristics, perceived higher cultural and religious barriers to receive COVID-19 vaccination were associated with lower COVID-19 vaccine uptake (AOR $0.83,95 \%$ CI $0.71-0.97 ; P=.02$ ). At the individual level, having more positive attitudes toward COVID-19 vaccination (AOR 1.31, 95\% CI 1.10-1.55; $P=.002$ ), perceived support from significant others (AOR 1.29, 95\% CI $1.03-1.60 ; P=.03)$, and perceived higher behavioral control to receive COVID-19 vaccination (AOR 2.63, 95\% CI 1.65-4.19; $P<.001)$ were associated with higher COVID-19 vaccine uptake,

while a negative association was found between negative attitudes and the dependent variable (AOR 0.73 , 95\% CI $0.62-0.85 ; P<.001)$. Knowing more peers who had received COVID-19 vaccination was also associated with higher uptake (AOR 1.39, 95\% CI 1.11-1.74; $P=.01$ ). At the interpersonal level, higher exposure to information about deaths and other serious conditions caused by COVID-19 vaccination was associated with lower uptake (AOR 0.54, 95\% CI 0.33-0.86; $P=.01$ ) (Table 4). 
Table 4. Factors associated with COVID-19 vaccine uptake among the South Asians who completed the web-based survey in Hong Kong on May $1-31,2021$

\begin{tabular}{|c|c|c|c|c|c|c|}
\hline Factors & $\begin{array}{l}\text { Participants who had } \\
\text { taken the COVID-19 } \\
\text { vaccine }(n=81)\end{array}$ & $\begin{array}{l}\text { Participants who } \\
\text { had not taken the } \\
\text { COVID-19 vaccine } \\
(n=164)\end{array}$ & $\begin{array}{l}\text { Crude odds ratio } \\
(95 \% \mathrm{CI})\end{array}$ & $P$ value & $\begin{array}{l}\text { Adjusted odds ratio } \\
(95 \% \mathrm{CI})\end{array}$ & $P$ value \\
\hline \multicolumn{7}{|l|}{ Individual-level factors, mean (SD) } \\
\hline Positive Attitude Scale & $13.6(1.7)$ & $12.2(2.5)$ & $1.31(1.17-1.56)$ & $<.001$ & $1.31(1.10-1.55)$ & .002 \\
\hline Negative Attitude Scale & $10.9(2.1)$ & $12.4(2.3)$ & $0.74(0.64-0.84)$ & $<.001$ & $0.73(0.62-0.85)$ & $<.001$ \\
\hline Subjective Norm Scale & $7.9(1.3)$ & $7.1(1.7)$ & $1.47(1.21-1.69)$ & $<.001$ & $1.29(1.03-1.60)$ & .03 \\
\hline Perceived Behavioral Control Scale & $5.7(0.7)$ & $4.9(1.2)$ & $2.70(1.82-4.00)$ & $<.001$ & $2.63(1.65-4.19)$ & $<.001$ \\
\hline $\begin{array}{l}\text { Among South Asians you know who } \\
\text { are living in Hong Kong-how many } \\
\text { of them have already taken up } \\
\text { COVID-19 vaccines? }\end{array}$ & $3.9(1.5)$ & $2.8(1.5)$ & $1.60(1.32-1.95)$ & $<.001$ & $1.39(1.11-1.74)$ & .01 \\
\hline \multicolumn{7}{|l|}{ Interpersonal-level factors } \\
\hline \multicolumn{7}{|c|}{ Frequency of exposure to the following information related to COVID-19 vaccination on social media, mean (SD) } \\
\hline $\begin{array}{l}\text { Positive information related to } \\
\text { COVID-19 vaccination }\end{array}$ & $1.8(0.8)$ & $1.6(0.9)$ & $1.32(0.95-1.82)$ & .10 & $1.16(0.78-1.72)$ & .46 \\
\hline $\begin{array}{l}\text { COVID-19 vaccination will } \\
\text { cause deaths and other serious } \\
\text { conditions }\end{array}$ & $1.3(0.6)$ & $1.5(0.8)$ & $0.67(0.46-0.98)$ & .04 & $0.54(0.33-0.86)$ & .01 \\
\hline $\begin{array}{l}\text { Many people in Hong Kong did } \\
\text { not turn up for their appoint- } \\
\text { ment to receive COVID-19 } \\
\text { vaccination }\end{array}$ & $1.3(0.8)$ & $1.3(0.8)$ & $0.99(0.71-1.37)$ & .94 & $0.98(0.66-1.56)$ & .92 \\
\hline \multicolumn{7}{|l|}{ Influence of peers, $n(\%)$} \\
\hline \multicolumn{7}{|c|}{ Did you hear about any South Asians who experienced serious side effects after taking up COVID-19 vaccines? } \\
\hline No & $65(80.2)$ & $123(75.0)$ & 1.0 & $\mathrm{~N} / \mathrm{A}^{\mathrm{b}}$ & 1.0 & N/A \\
\hline Yes & $16(19.8)$ & $41(25.0)$ & $0.74(0.39-1.42)$ & .36 & $0.69(0.31-1.52)$ & .35 \\
\hline \multicolumn{7}{|l|}{ Sociostructural-level factors, mean (SD) } \\
\hline Cultural and Religious Barrier Scale & $7.5(2.1)$ & $8.7(2.6)$ & $0.81(0.72-0.91)$ & .001 & $0.83(0.71-0.97)$ & .02 \\
\hline $\begin{array}{l}\text { Level of confidence in Hong Kong's } \\
\text { health system }\end{array}$ & $7.4(2.4)$ & $7.2(2.0)$ & $1.06(0.93-1.21)$ & .36 & $0.95(0.82-1.11)$ & .53 \\
\hline $\begin{array}{l}\text { Level of trust of the Hong Kong } \\
\text { government regarding COVID-19 } \\
\text { control }\end{array}$ & $8.2(1.9)$ & $7.5(2.2)$ & $1.18(1.03-1.36)$ & .02 & $1.09(0.92-1.29)$ & .33 \\
\hline
\end{tabular}

${ }^{a}$ Odds ratio adjusted for significant background characteristics (age group, relationship status, ethnicity, permanent residents of Hong Kong, frequency of facemask wearing in public spaces/transportation other than workplaces, sanitizing hands after returning form public spaces or touching public installation, and avoiding social/meal gathering with other people who do not live together).

${ }^{\mathrm{b}} \mathrm{N} / \mathrm{A}$ : not applicable.

\section{Discussion}

To our knowledge, this is one of the first studies investigating the determinants of COVID-19 vaccine uptake by using the socioecological perspective among ethnic minorities. About one-third of the participants received at least one dose of COVID-19 vaccination. Factors at the individual level (perceptions related to COVID-19 vaccination), interpersonal level (influence of social media), and sociostructural level (cultural belief) were determinants of the COVID-19 vaccine uptake. Using the socioecological model allows us to understand
COVID-19 vaccination behaviors from a comprehensive perspective.

Participants aged 30-49 years reported the highest COVID-19 vaccine uptake; this finding was different from that reported in the Chinese population [23-26]. Married or cohabitation with a partner was also associated with higher COVID-19 vaccine uptake. Future studies should confirm whether protecting one's partner is the motivation to receive COVID-19 vaccination. In addition, South Asians who were not Hong Kong permanent residents reported lower COVID-19 vaccine uptake. Nonpermanent residents might be less familiar with the health care system in Hong Kong and should receive more support in 
future programs. As for COVID-19 preventive behaviors, similar to that reported in previous studies $[19,22]$, higher compliance to personal preventive behaviors (eg, consistent facemask wearing in public spaces and hand hygiene) and physical distancing behaviors (eg, avoiding social/meal gathering) was associated with higher uptake.

Culturally, our findings also showed that Pakistanis reported significantly lower COVID-19 vaccine uptake compared to Indians. Differences in the religious belief might partially explain this variation. Islam is the major religion for Pakistanis, and news reported concerns about the halal status of COVID-19 vaccines among Muslims [13]. Our findings suggested that some unique strategies should be tailored for South Asians to address cultural and religious reasons for COVID-19 vaccination hesitancy. The results confirmed that concerns about the halal status of COVID-19 vaccines was a barrier for South Asians to take up the vaccines [15]. The government should work with the vaccine manufacturers to clarify whether gelatin, which has been commonly used as a stabilizer for the safety and effectiveness of vaccines during storage and transportation, is a part of the available COVID-19 vaccines. In order to address other cultural or religious issues, future programs should engage community groups, champions and faith leaders, and develop culturally competent interventions.

At the individual level, South Asians shared some similar facilitators as the local Chinese population to receive COVID-19 vaccination, including perceived efficacy of COVID-19 vaccination in protecting themselves and their family members, perceived impacts of COVID-19 vaccination on pandemic control, perceived support from significant others, and perceived behavioral control of taking up COVID-19 vaccination [23-26]. Concerns about side effects and difficulties in choosing the most suitable COVID-19 vaccine were common barriers [23-26]. Therefore, the same health promotion strategies might be useful for both South Asians and Chinese in Hong Kong. In order to prevent the choice overload [21], efficacies and side effects of different COVID-19 vaccines available in Hong Kong can be compared on a table, which makes it easy for participants to compare features across products [21]. Laymen's terms in participants' native language should be used to emphasize that severe side effects of COVID-19 vaccination are rare, and the pros of vaccination outweigh its cons. Testimonials of people who received different types of COVID-19 vaccines regarding side effects should be presented. Health communication messages should also demonstrate that the procedures to receive vaccination are easy and convenient to reduce concerns regarding vaccination procedures. The recommendation made by health care providers is a strong facilitator of COVID-19 vaccine uptake [23-26]. Performing outreach vaccination services in South Asian communities is also useful for enhancing their perceived behavioral control. The results also supported a significant influence of peers on COVID-19 vaccine uptake among South Asians. Updated information about how many South Asians had received COVID-19 vaccination should be disseminated to this group. At the interpersonal level, exposure to negative information about COVID-19 negatively affects vaccine uptake. Health authorities in Hong Kong should identify and address common misinformation in a timely manner. It is encouraging that the government has started to clarify this misinformation on the vaccination program webpage.

The findings of this study should be interpreted in light of some limitations. First, a direct measure of perceived behavioral control should assess self-efficacy and perceived controllability $[29,30]$. Previous studies have suggested that these 2 constructs were differently associated with behavioral intention and actual behaviors [29,30]. In this study, the scale measuring perceived behavioral control was adapted from a validated tool [19]. Owing to the limited length of the questionnaire, the measurement only had 2 items and mainly covered self-efficacy. Failure to measure perceived controllability together with self-efficacy was one major limitation of this study. Second, in the absence of a sampling frame, participants were conveniently recruited online. Similar to other web-based surveys, the response rate was relatively low (about $25 \%$ ). We were not able to obtain the characteristics of the active WhatsApp contacts who did not respond to our invitation or refused to complete the survey. Therefore, we were not able to compare the characteristics of the respondents and nonrespondents. There was a selection bias. Generalizations should be made cautiously to South Asians in Hong Kong. Yet, because ethnic minorities is a special population in Hong Kong, using the traditional randomly sampling method of telephone or mail survey was not feasible for administering the questionnaire to this targeted population. Third, some items and scales used in this study were single items, self-constructed, or modified from those used in published studies in the general population. We purposely decided not to use standardized western scale measurements to account for the cultural variations experienced by the ethnic minorities in Hong Kong. A self-constructed or modified scale that is designed to suit the local context of Hong Kong is more suitable. Furthermore, the use of a single-item scale will significantly decrease the burden of the respondents who need to take time to complete the survey. Moreover, this was a cross-sectional study and could not establish causal relationships.

Using the socioecological model, this study offered an overview for us to identify tapping points that can encourage COVID-19 vaccine uptake among South Asian populations in Hong Kong. Because they shared cultural and social orientations dissimilar from those of the local Chinese in Hong Kong, current empirical evidence offered a guide on how promotional strategies can be customized for this population. We recommend religion-targeted, outreach community, and peer-based programs to enhance COVID-19 vaccine uptake rate among South Asians in Hong Kong. To further customize the promotion, these programs can be co-designed, shared, and endorsed by South Asian communities such as nonprofit groups, champions, and faith leaders to develop culturally competent interventions. 


\section{Acknowledgments}

We would like to thank all the participants in this study and the staff who contributed during the data collection process. The Centre for Health Systems and Policy Research is funded by the Tung Foundation.

\section{Authors' Contributions}

AS, AHYL, ZW, and EKY conceptualized this study. AS, AHYL, JW, SA, PSFC, and ZW performed the methodology in this study. Data were curated by AS, AHYL, JW, and ZW. AS, AHYL, and ZW conducted the formal analysis and the project administration. AHYL, ZW, and EKY provided the resources and supervised the study. AS, AHYL, PSFC, and ZW wrote the original draft. AS, AHYL, JW, SA, PSFC, ZW, and EKY reviewed and edited the manuscript. Funds were acquired by AHYL, ZW, and EKY. AS and AHYL contributed equally as first authors. ZW and EKY contributed equally as corresponding authors. All authors have read and agreed to the final manuscript.

\section{Conflicts of Interest}

None declared.

\section{Multimedia Appendix 1}

English version of the questionnaire survey.

[DOCX File, $31 \mathrm{~KB}-$ Multimedia Appendix 1]

\section{References}

1. Coronavirus disease (COVID-19) in Hong Kong. The Government of the Hong Kong SAR. URL: https://www. coronavirus.gov.hk/eng/index.html [accessed 2021-03-09]

2. Consensus interim recommendation on the use of COVID-19 vaccines in Hong Kong. Centre for Health Protection. URL: https://www.chp.gov.hk/files/pdf/consensus interim recommendations on the use of covid19 vaccines inhk.pdf [accessed 2021-03-01]

3. Anderson RM, Vegvari C, Truscott J, Collyer BS. Challenges in creating herd immunity to SARS-CoV-2 infection by mass vaccination. Lancet 2020 Nov 21;396(10263):1614-1616 [FREE Full text] [doi: 10.1016/S0140-6736(20)32318-7] [Medline: $\underline{33159850]}$

4. COVID-19 vaccination program statistics. The Government of the Hong Kong Special Administrative Region. URL: https:/ /www.info.gov.hk/gia/general/202105/01/P2021050100801.htm?fontSize=1 [accessed 2021-06-22]

5. Razai MS, Kankam HKN, Majeed A, Esmail A, Williams DR. Mitigating ethnic disparities in COVID-19 and beyond. BMJ 2021 Jan 14;372:m4921. [doi: 10.1136/bmj.m4921] [Medline: 33446485]

6. New poll finds ethnic minority groups less likely to want COVID vaccine. Royal Society for Public Health. URL: https:/ /www.rsph.org.uk/about-us/news/new-poll-finds-bame-groups-less-likely-to-want-covid-vaccine.html [accessed 2021-06-22]

7. Robinson E, Jones A, Lesser I, Daly M. International estimates of intended uptake and refusal of COVID-19 vaccines: A rapid systematic review and meta-analysis of large nationally representative samples. Vaccine 2021 Apr 08;39(15):2024-2034 [FREE Full text] [doi: 10.1016/j.vaccine.2021.02.005] [Medline: 33722411]

8. Robertson E, Reeve KS, Niedzwiedz CL, Moore J, Blake M, Green M, et al. Predictors of COVID-19 vaccine hesitancy in the UK household longitudinal study. Brain Behav Immun 2021 May;94:41-50 [FREE Full text] [doi: 10.1016/j.bbi.2021.03.008] [Medline: 33713824]

9. MacKenna B, Curtis H, Morton C, Inglesby P, Walker A, Morley J. Trends, regional variation, and clinical characteristics of COVID-19 vaccine recipients: a retrospective cohort study in 23.4 million patients using OpenSAFELY. medRxiv. Preprint posted online on April 9, 2021. [FREE Full text] [doi: 10.1101/2021.01.25.21250356]

10. Martin C, Marshall C, Patel P, Goss C, Jenkins D, Ellwood C. Association of demographic and occupational factors with SARS-CoV-2 vaccine uptake in a multi-ethnic UK health care workforce: a rapid real-world analysis. medRxiv. Preprint posted online on February 18, 2021. [doi: 10.1101/2021.02.11.21251548]

11. Thematic report: ethnic minorities. Census and Statistics Department. URL: http://www.statistics.gov.hk/pub/ B11200502006XXXXB0100.pdf [accessed 2021-06-22]

12. Vandan N, Wong J, Gong W, Yip P, Fong D. Health system responsiveness in Hong Kong: a comparison between South Asian and Chinese patients' experiences. Public Health 2020 May;182:81-87. [doi: 10.1016/j.puhe.2020.01.019] [Medline: 32200074]

13. McLeroy KR, Bibeau D, Steckler A, Glanz K. An ecological perspective on health promotion programs. Health Educ Q 1988;15(4):351-377. [doi: 10.1177/109019818801500401] [Medline: 3068205]

14. Syed Alwi SAR, Rafidah E, Zurraini A, Juslina O, Brohi IB, Lukas S. A survey on COVID-19 vaccine acceptance and concern among Malaysians. BMC Public Health 2021 Jun 12;21(1):1129 [FREE Full text] [doi: 10.1186/s12889-021-11071-6] [Medline: $\underline{34118897]}$ 
15. Concern among Muslims over halal status of COVID-19 vaccine. Arab News. URL: https://www.arabnews.com/node/ 1780091/world [accessed 2021-06-22]

16. Guy J. WESH 2 exclusive: religion and the COVID-19 vaccine. WESH 2. URL: https://www.wesh.com/article/ religion-and-the-covid-19-vaccine/36327359 [accessed 2021-06-22]

17. Horton R. Offline: Managing the COVID-19 vaccine infodemic. Lancet 2020 Nov 07;396(10261):1474 [FREE Full text] [doi: 10.1016/S0140-6736(20)32315-1] [Medline: 33160553]

18. Taylor J, Eitle D, Russell D. Racial/ethnic variation in the relationship between physical limitation and fear of crime: An examination of mediating and moderating factors. Deviant Behav 2009 Feb 01;30(2):144-174 [FREE Full text] [doi: 10.1080/01639620802050213] [Medline: 19777085 ]

19. Zhang KC, Fang Y, Cao H, Chen H, Hu T, Chen Y, et al. Behavioral Intention to Receive a COVID-19 Vaccination Among Chinese Factory Workers: Cross-sectional Online Survey. J Med Internet Res 2021 Mar 09;23(3):e24673 [FREE Full text] [doi: $10.2196 / 24673]$ [Medline: $\underline{33646966}$ ]

20. Huang X, Yu M, Fu G, Lan G, Li L, Yang J, et al. Willingness to Receive COVID-19 Vaccination Among People Living With HIV and AIDS in China: Nationwide Cross-sectional Online Survey. JMIR Public Health Surveill 2021 Oct 21;7(10):e31125 [FREE Full text] [doi: 10.2196/31125] [Medline: 34543223]

21. Chernev A, Böckenholt U, Goodman J. Choice overload: A conceptual review and meta-analysis. Journal of Consumer Psychology 2015 Apr;25(2):333-358. [doi: 10.1016/j.jcps.2014.08.002]

22. Zhang KC, Fang Y, Cao H, Chen H, Hu T, Chen YQ, et al. Parental Acceptability of COVID-19 Vaccination for Children Under the Age of 18 Years: Cross-Sectional Online Survey. JMIR Pediatr Parent 2020 Dec 30;3(2):e24827 [FREE Full text] [doi: 10.2196/24827] [Medline: $\underline{33326406]}$

23. Wong MC, Wong EL, Huang J, Cheung AW, Law K, Chong MK, et al. Acceptance of the COVID-19 vaccine based on the health belief model: A population-based survey in Hong Kong. Vaccine 2021 Feb 12;39(7):1148-1156 [FREE Full text] [doi: 10.1016/j.vaccine.2020.12.083] [Medline: 33461834]

24. Wang K, Wong EL, Ho K, Cheung AW, Yau PS, Dong D, et al. Change of Willingness to Accept COVID-19 Vaccine and Reasons of Vaccine Hesitancy of Working People at Different Waves of Local Epidemic in Hong Kong, China: Repeated Cross-Sectional Surveys. Vaccines (Basel) 2021 Jan 18;9(1):62 [FREE Full text] [doi: 10.3390/vaccines9010062] [Medline: 33477725]

25. Yu Y, Lau JT, Lau MM, Wong MC, Chan PK. Understanding the Prevalence and Associated Factors of Behavioral Intention of COVID-19 Vaccination Under Specific Scenarios Combining Effectiveness, Safety, and Cost in the Hong Kong Chinese General Population. Int J Health Policy Manag. Preprint posted online on January 18, 2021. [doi: 10.34172/ijhpm.2021.02] [Medline: 33619928]

26. CityU survey indicates background and trust in government affect citizens' willingness to receive coronavirus vaccines. City University of Hong Kong. URL: https://www.cityu.edu.hk/media/press-release/2021/02/24/ cityu-survey-indicates-background-and-trust-government-affect-citizens-willingness-receive-coronavirus-vaccines [accessed 2021-02-24]

27. Pan Y, Fang Y, Xin M, Dong W, Zhou L, Hou Q, et al. Self-Reported Compliance With Personal Preventive Measures Among Chinese Factory Workers at the Beginning of Work Resumption Following the COVID-19 Outbreak: Cross-Sectional Survey Study. J Med Internet Res 2020 Sep 29;22(9):e22457 [FREE Full text] [doi: 10.2196/22457] [Medline: 32924947]

28. Pan Y, Xin M, Zhang C, Dong W, Fang Y, Wu W, et al. Associations of Mental Health and Personal Preventive Measure Compliance With Exposure to COVID-19 Information During Work Resumption Following the COVID-19 Outbreak in China: Cross-Sectional Survey Study. J Med Internet Res 2020 Oct 08;22(10):e22596 [FREE Full text] [doi: 10.2196/22596] [Medline: $\underline{\text { 32936776] }}$

29. Ajzen I. Perceived Behavioral Control, Self-Efficacy, Locus of Control, and the Theory of Planned Behavior. Journal of Applied Social Psychology 2002;32:665-683. [doi: 10.1111/j.1559-1816.2002.tb00236.x]

30. Cooke R, Dahdah M, Norman P, French DP. How well does the theory of planned behaviour predict alcohol consumption? A systematic review and meta-analysis. Health Psychol Rev 2016 Jun;10(2):148-167 [FREE Full text] [doi: 10.1080/17437199.2014.947547] [Medline: 25089611]
Abbreviations
AOR: adjusted odds ratio
CBO: community-based organization
TPB: Theory of Planned Behavior 
Edited by T Sanchez; submitted 01.07.21; peer-reviewed by S Tomczyk, S Pesälä; comments to author 21.09.21; revised version received 09.10.21; accepted 12.10.21; published 09.11.21

Please cite as:

Singh A, Lai AHY, Wang J, Asim S, Chan PSF, Wang Z, Yeoh EK

Multilevel Determinants of COVID-19 Vaccine Uptake Among South Asian Ethnic Minorities in Hong Kong: Cross-sectional Web-Based Survey

JMIR Public Health Surveill 2021;7(11):e31707

URL: https://publichealth.jmir.org/2021/11/e31707

doi: $\underline{10.2196 / 31707}$

PMID: $\underline{34653014}$

(C)Akansha Singh, Angel Hor Yan Lai, Jingxuan Wang, Saba Asim, Paul Shing-Fong Chan, Zixin Wang, Eng Kiong Yeoh. Originally published in JMIR Public Health and Surveillance (https://publichealth.jmir.org), 09.11.2021. This is an open-access article distributed under the terms of the Creative Commons Attribution License (https://creativecommons.org/licenses/by/4.0/), which permits unrestricted use, distribution, and reproduction in any medium, provided the original work, first published in JMIR Public Health and Surveillance, is properly cited. The complete bibliographic information, a link to the original publication on https://publichealth.jmir.org, as well as this copyright and license information must be included. 